\begin{tabular}{c|c|c}
\hline \hline & CLIMATE RESEARCH & Published April 26 \\
Vol. 20: $253-257,2002$ & Clim Res & \\
\hline
\end{tabular}

\title{
Climate change as a threat to tourism in the Alps
}

\author{
Hans Elsasser*, Rolf Bürki \\ Economic Geography Division, Department of Geography, University of Zurich-Irchel, Winterthurerstr. 190, \\ 8057 Zurich, Switzerland
}

\begin{abstract}
Switzerland's economy depends heavily on tourism. For many alpine areas in the country, winter tourism is the most important source of income, and snow-reliability is one of the key elements of the offers made by tourism in the Alps. The financial viability of winter tourism, however, depends on sufficient snow conditions. The lack of snow at the end of the 1980s left a lasting imprint on the tourism industry. If the assumptions of the impacts of climate change hold true, snow cover in the Swiss Alps will diminish, and this will, in turn, jeopardise the tourism industry. $85 \%$ of Switzerland's current ski resorts can be designated as snow-reliable. If climate change occurs, the level of snow-reliability will rise from $1200 \mathrm{~m}$ up to $1800 \mathrm{~m}$ over the next few decades. Only $44 \%$ of the ski resorts would then still be snow-reliable. While some regions may be able to maintain their winter tourism with suitable adaptation strategies, others would lose all winter tourism due to a diminishing snow pack. Despite global warming, it is impossible to exclude the possibility of winters with heavy snowfall in the future (e.g. the winter of 1998/99, particularly February 1999). Climate change must be viewed as a catalyst that is reinforcing and accelerating the pace of structural changes in tourism. Today, adaptation strategies are predominant in tourism (e.g. artificial snow production). As an industry that will be severely affected by climate change, however, tourism will increasingly have to focus on mitigation strategies (e.g. less greenhouse gas emissions by tourism traffic).
\end{abstract}

KEY WORDS: Climate change $\cdot$ Tourism $\cdot$ Skiing $\cdot$ Snow $\cdot$ Alps $\cdot$ Switzerland Resale or republication not permitted without written consent of the publisher

\section{INTRODUCTION}

In the winter of $1997 / 98$, snow-reliability received high rankings amongst the 'top-10 requirements' of holiday guests in Switzerland. Eighty-one percent of the guests questioned in the 'TOP Swiss-Tourism Profile Switzerland' regard this as an important aspect (Bundesamt für Statistik 1999).

Snow-reliability is a key element of offers made by ski tourism in the alpine region, and ski tourism, which depends on a sufficient amount of snow, is a key element in the tourism industry in the Alps. The crucial factor for the long-term survival of mountain cableway companies is the frequency and regularity of winters with good snow conditions, or, put the other way round, the number of snow-deficient winters that can be withstood. It is not possible to give a definitive

*E-mail: elsasser@geo.unizh.ch answer here, since the economic situation of the companies varies too much. The experience acquired by Swiss ski resorts, however, shows that a ski resort can be considered snow-reliable if, in 7 out of 10 winters, a sufficient snow covering of at least 30 to $50 \mathrm{~cm}$ is available for ski sport on at least $100 \mathrm{~d}$ between December 1 and April 15 (Bürki 2000, p. 42).

Good snow conditions are a necessity, although they are not the only prerequisite for a financially viable mountain cable-way company. Without enough snow, however, profitable ski tourism will scarcely be possible. Apart from having sufficient snow at the right time-and particularly during the Christmas/New Year holidays - a key role is also played by the weather conditions (predominantly at the weekends). Since weekend and day guests are planning their trips at ever-shorter notice, it is not just the actual weather conditions which are a growing factor of influence, but the weather forecasts too (Grischconsulta 1999, p. 7.9).

(C) Inter-Research $2002 \cdot$ www.int-res.com 
It is very probable that climate change will lower the reliability of snow cover. Considering the high sensitivity of winter tourism to snow-deficient winters, climate change would severely affect the tourism industry. Meier (1998) calculated the potential annual costs of climate change in Switzerland at CHF 2.3 to 3.2 billion (US $\$ 1.4$ to 1.9 billion) by the year 2050, which is 0.6 to $0.8 \%$ of the Swiss gross national product for 1995. CHF 1.8 to 2.3 billion (US $\$ 1.1$ to 1.4 billion) would be accounted for by tourism. Even if there are many reservations that can be voiced regarding this calculation, it nevertheless shows that tourism is the economic sector that would be most affected by climate change in Switzerland and that this influence is of an order of magnitude that cannot be neglected.

\section{SNOW-DEFICIENT WINTERS}

It was the winters with little snow at the end of the 1980s (1987/88-1989/90) that caused a stir. The big difference to earlier periods with little snow was that the capital intensity of ski tourism had considerably increased.

The snow shortage at the end of the 1980s left a clear mark on the tourist trade. The earnings of cable-way companies decreased by $20 \%$ compared to the 'normal' winter of 1986/1987. Particularly affected were smaller companies at lower and medium altitudes. A number of companies in regions above $1700 \mathrm{~m}$ achieved good and even first-rate results due to the lack of snow at lower and medium altitudes.

The slump in the hotel and holiday-apartment trade was less pronounced, as they also accommodate nonskiers. Hotel rooms and holiday apartments also tend to be booked quite a long time in advance. The question does arise, however, as to how long tourists will remain loyal to a location and keep returning to it if they are repeatedly confronted with inadequate snow conditions.

\section{CLIMATE CHANGE-SNOW RELIABILITY - SKI TOURISM}

In the Swiss Alps, the altitude at which snow is sufficient for skiing is $1200 \mathrm{~m}$ above sea level (masl) (Föhn 1990 , p. 45). Thus, $85 \%$ of Switzerland's 230 ski resorts can be considered to be snow-reliable today, while the figure for the 122 individual ski-lifts located at much lower altitudes is $40 \%$ (Table 1 ). If the line of snowrelability were to rise up to 1500 masl as a result of climate change, the number of snow-reliable ski resorts would drop to $63 \%$ and to $9 \%$ for individual ski-lifts, respectively. The Jura, Eastern and Central Switzerland, Ticino, and the Alps in the cantons of Vaud and Fribourg would be particularly jeopardised. The ski regions of Valais and the Grisons will experience virtually no major problems, since the mean altitude of the cable-way terminals in these regions is higher than 2500 masl (Abegg 1996). If the line of snow-reliability were to rise to 1800 masl, which is a possible scenario (Bürki 2000), then there would be a further serious deterioration in conditions: only $44 \%$ of skiing regions and $2 \%$ of individual ski-lifts could be designated as snow-reliable. The Jura would lose its alpine skiing. Even in the cantons of Grisons and Valais, approximately a quarter of the skiing regions would no longer be snow-reliable.

Climate change will lead to a new pattern of favoured and disadvantaged ski tourism regions. If all other influencing factors remain the same, ski tourism will concentrate in the high-altitude areas that are snow-reliable in the future too, e.g. most of the ski runs in the cantons of Valais and Grisons. Ski resorts at lower altitudes will withdraw from the market sooner or later because of the lack of snow. The only areas with good prospects will be those with transport facilities that provide access to altitudes higher than 2000 masl. The regions at higher altitudes may experience greater demand, prompting a further expansion in quantitative terms. The pressure on ecologically

Table 1. Snow reliability of Swiss ski resorts (Abegg 1996, p. 127, Bürki 2000, p. 61). masl: metres above sea level

\begin{tabular}{|c|c|c|c|c|c|c|c|}
\hline \multirow[t]{3}{*}{ Region } & \multirow{3}{*}{ Number of ski resorts } & \multicolumn{6}{|c|}{ Snow-reliability } \\
\hline & & \multicolumn{2}{|c|}{1200 masl } & \multicolumn{2}{|c|}{1500 masl } & \multicolumn{2}{|c|}{1800 masl } \\
\hline & & No. & $\%$ & No. & $\%$ & No. & $\%$ \\
\hline Jura & 15 & 4 & 27 & 1 & 7 & 0 & 0 \\
\hline Alps (Vaud + Fribourg) & 19 & 16 & 84 & 7 & 37 & 4 & 21 \\
\hline Valais & 54 & 54 & 100 & 52 & 96 & 40 & 74 \\
\hline Bern (ex. Jura) & 35 & 30 & 86 & 20 & 57 & 12 & 34 \\
\hline Central Switzerland & 35 & 26 & 74 & 13 & 37 & 7 & 20 \\
\hline Ticino & 8 & 8 & 100 & 3 & 38 & 2 & 25 \\
\hline Eastern Switzerland & 18 & 11 & 61 & 6 & 33 & 3 & 17 \\
\hline Grisons & 46 & 46 & 100 & 42 & 91 & 33 & 72 \\
\hline Switzerland & 230 & 195 & 85 & 144 & 63 & 101 & 44 \\
\hline
\end{tabular}


sensitive high-mountain regions will increase. The call for snow-reliable ski resorts constitutes the main reason for the current boom in concept studies and plans for opening up high-mountain regions, or, expressed in different terms: climate change is an argument for opening up high-mountain regions to tourism.

However, the winter of 1998/99, in particular, February 1999, showed that the possibility of winters with a great deal of snow cannot be excluded in the future. In a study of the 'avalanche winter' of 1999 (SLF 2000), the direct losses incurred by mountain cable-ways as a result of avalanches and the large quantities of snow were estimated at CHF 15 million (US \$ 9 million). In total, 36 facilities were damaged, including 20 ski-lifts, 11 chair-lifts, 4 cable railways and 1 funicular. The mountain railway companies had to spend an extra $77 \%$ on snow clearing, compared with previous years. Roughly $25 \%$ more than in normal winters was spent on securing the ski slopes (Grischconsulta 1999, p. 12). All in all, the avalanche winter of 1999 probably caused losses in excess of CHF 200 million (US \$ 120 million), the major portion of these having been indirect losses (SLF 2000).

\section{ADAPTATIONS OF TOURISM REPRESENTATIVES}

The tourism representatives at a political, entrepreneurial, operational and organisational level are not sitting back idly contemplating the consequences of a climate change. They are adapting right now in the expectation of climate change. The experiences with snow-deficient winters has shown them that the climate does not determine their economic activities, but, instead, constitutes a key resource and framework condition.

Bürki (2000) investigated how tourism representatives perceive climate change in Central Switzerland and how they believe they would adapt. The results of the study, carried out with the so-called 'focus-group method' (see Dürrenberger \& Behringer 1999), can be summed up as follows:

Climate change has been recognised as a problem for winter tourism. Those responsible for tourism know that what they can offer is highly dependent on snow and that they are at risk from snow-deficient winters. They are familiar with the potential consequences of climate change for winter tourism. While achieving snow-reliability constitutes a central topic, potential climatic change is seen as being only of relatively minor importance.

Climate change is not regarded as a catastrophe for winter tourism. The tourism representatives think that climatic change is presented in a highly exaggerated form by the media-and also in science and politics. Although climate change could intensify the problems that already exist in ski areas at lower altitudes and speed up structural changes in the sector, the majority of ski resorts at medium and high altitudes, however, would scarcely be affected. Climate change is already affecting the strategies and plans of the winter sport resorts today. The discussions held in the focus groups clearly revealed an ambivalent relationship to climate change. On the one hand, the representatives strongly distrust the information disseminated about climate change and play down its potential consequences, but on the other hand, they use climate change to legitimate forward strategies. Climate change and global warming, together with international competition, have been used as the key arguments for constructing artificial snow-making facilities, as well as for extending existing ski runs and opening new ones in highalpine regions (at above 3000 masl).

The tourism representatives all agree that winter sports can only survive in the Alps if snow-reliability is guaranteed. Precisely, the smaller ski fields at lower altitudes either have their hands bound or can scarcely finance the necessary investments (e.g. snow cannons, levelling out ski slopes, opening higher-altitude chambers in skiing areas). On the one hand, they do not have financial resources of their own, and on the other hand, banks are (now) only prepared to grant very restrictive loans to ski resorts at altitudes below 1500 masl which are not particularly profitable. Nevertheless, the representatives believe that smaller ski fields in the Alpine foothills play a key role in promoting the importance of skiing. Opinions frequently differ a great deal, however, on whether non-profitable ski regions of this type should be retained and how their financing can be guaranteed. While a number of people are in favour of dismantling non-profitable cable-way and ski-lift operations and regard a certain 'healthy shrinkage' of the sector as necessary, others believe that there is an obligation to retain these ski fields for regional economic reasons. This is also increasing pressure for cable-way companies to receive subsidies (see also Grischconsulta 1999, p. 28).

\section{STRATEGIES}

Climate change represents a new challenge for tourism, and particularly for winter tourism in the Alps. It is not, however, the case that tourism's initial position will undergo a sudden, radical change. Instead, climate change has to be viewed as a catalyst that will reinforce and accelerate the pace of structural change in the tourist industry and more clearly highlight the risks and opportunities inherent in tourist develop- 


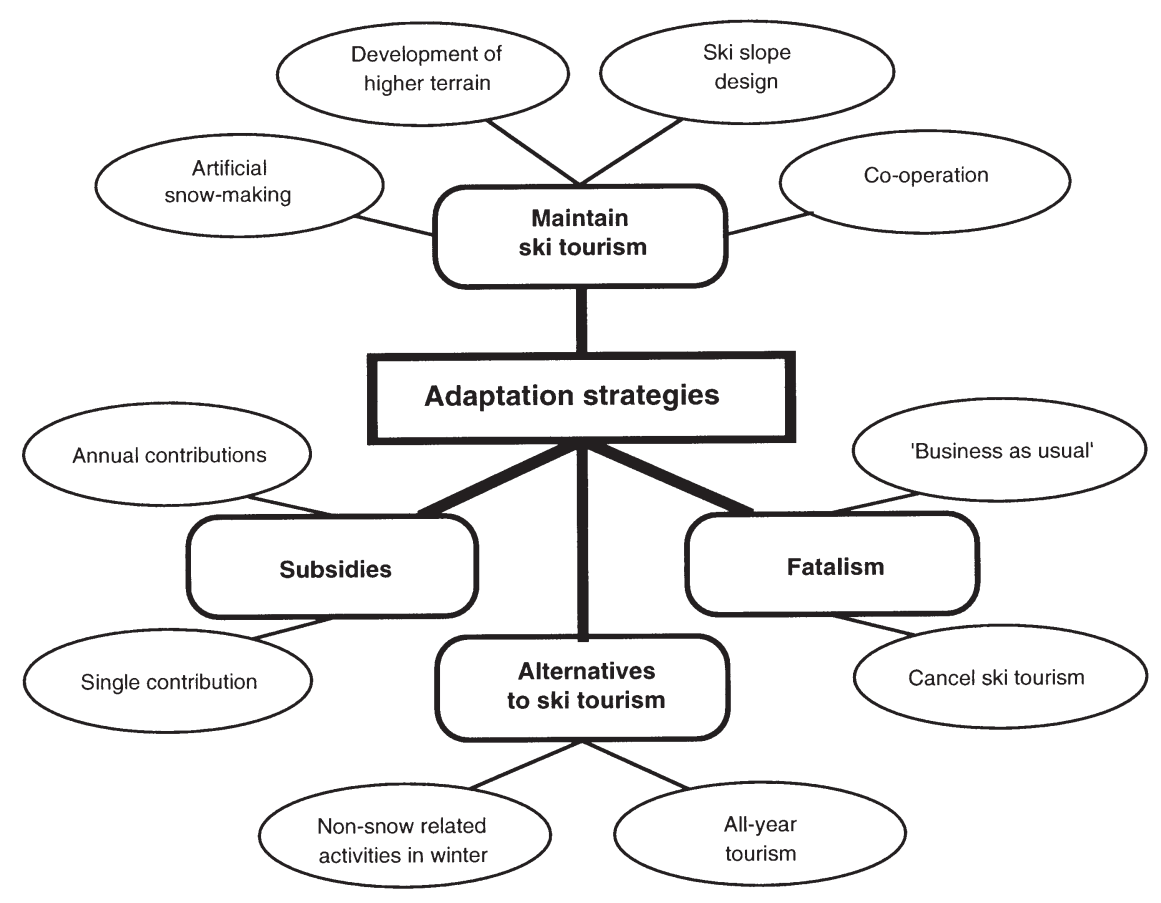

Fig. 1. Adaption stategies

ments even now. The emergence of a 2-tier society in the tourist sector will not be due to climate change alone, but to the general change in structure as well. On the one hand, we have the top resorts with their already varied and attractive offers and high snowreliability and, on the other hand, we have the smaller locations with their less-extensive developments, lessrefined offers and restricted opportunities for further development.

Since climate change is a relatively long-term development in comparison to other trends in tourism, tourism managers and tourists will have every opportunity to adjust to the different constraints and adopt the corresponding strategies and measures (Fig. 1). One of the most familiar measures in the struggle against snow-deficient winters is the construction of artificial snow-making facilities. However, the investment costs per kilometre of ski-slope served by snow cannons is approximately CHF 1 million (US \$ 0.6 million), while the annual operating costs per kilometre of ski-slope with artificial snow are between CHF 30000 and 50000 (US $\$ 18000$ to 30000 ) (Ammann 1999, p. 159-160).

Adopting a fatalistic attitude towards climate change and its impacts should not be considered as a true strategy in this respect. Such attitudes are manifested by the fact that neither suppliers nor consumers alter their behaviour. This could also be described by using the term 'business as usual'. Another approach that can be classified under the heading of 'fatalism' is when tourist transport facilities that were used for winter sports are closed down and dismantled without any attempt at promoting and reinforcing other types of tourism - in other words, when withdrawal from ski tourism is not actively planned. A fatalistic attitude of this type is most readily evident amongst the operators of small, isolated ski-lifts at lower altitudes who experienced severe financial difficulties as a result of the snow-deficient winters.

As a sector of the economy that is severely affected by climate change, however, tourism needs to focus more on mitigation strategies in its own best interests. This holds particularly true for the traffic generated by national and international tourism and, above all, for air traffic. Leisure and tourist traffic already accounts for approximately half of all passenger traffic in Switzerland today (expressed in terms of the number of kilometres travelled per person). Tourism accounts for approximately $60 \%$ of air passengers and $70 \%$ of the kilometres flown world-wide. Tourist development and tourist projects not only need to be verified and evaluated in terms of their social and environmental compatibility but must also be assessed from the climate-compatibility angle.

\section{CONCLUSIONS}

Winter tourism depends on good snow conditions and is highly sensitive to snow-deficient winters. Cli- 
mate research findings show that there will be an increase in the number of winters with little snow on account of climate change. The tourism representatives will not just sit back idly in the face of climate change. They are reacting to the deteriorating snow conditions and the changes in demand. Technical measures, especially artificial snow-making, to maintain ski tourism rank at the forefront. Tourists demand good snow conditions, and hence, this is what has to be offered by the ski resorts. The impacts of climate change will involve significant costs for tourism in Switzerland. Behind these costs are the people who are directly affected, whose personal fate this is, and who will lose their livelihoods through climate change. They will not be able to adapt as flexibly as the tourists, who will simply travel to a different ski resort with good snow conditions.

\section{LITERATURE CITED}

Abegg B (1996) Klimaänderung und Tourismus_Klimafolgenforschung am Beispiel des Wintertourismus in den

Editorial responsibility: Hans von Storch,

Geesthacht, Germany
Schweizer Alpen. Schlussbericht NFP 31. vdf Zürich

Ammann W (1999) Schnee und Lawinen-Bestimmende Wirtschaftsfaktoren im Alpenraum. In: Université de Genève et Institut universitaire Kurt Bösch (Hrsg): Die Rolle des Wassers in der sozio-ökonomischen Entwicklung der Alpen. Institut universitaire Kurt Bösch, Sion, p 139-162

Bürki R (2000) Klimaänderung und Anpassungsprozesse im Tourismus - dargestellt am Beispiel des Wintertourismus. Publikation der Ostschweizerischen Geographischen Gesellschaft NF H 6, St. Gallen

Bundesamt für Statistik (1999) Schweizer Tourismus in Zahlen. STV, Bern

Dürrenberger G, Behringer J (1999) Die Fokusgruppe in Theorie und Anwendung. Akademie für Technikfolgenabschätzung in Baden-Württemburg, Stuttgart

Föhn P (1990) Schnee und Lawinen. In: Schnee, Eis und Wasser der Alpen in einer wärmeren Atmosphäre. Internationale Fachtagung, Mitteilungen VAW ETH Zürich No. 108, Zürich, p 33-48

Grischconsulta (1999) Bergbahnen wohin?-Ausgabe 1999. Grischconsulta, Chur

Meier R (1998) Sozioökonomische Aspekte von Klimaänderungen und Naturkatastrophen in der Schweiz. Schlussbericht NFP 31. vdf, Zürich

SLF (Eidg Institut für Schnee- und Lawinenforschung) (2000) Der Lawinenwinter 1999-Ereignisanalyse. SLF, Davos

Submitted: December 4, 2000; Accepted: November 11, 2001 Proofs received from author(s): February 18, 2002 